\title{
In vitro SUSCEPTIBILITY TO ANTIFUNGAL AGENTS OF CLINICAL AND ENVIRONMENTAL Cryptococcus neoformans ISOLATED IN SOUTHERN OF BRAZIL
}

\author{
Sydney Hartz ALVES(1), Loiva T. OLIVEIRA(2), Jane M. COSTA(2), Irina LUBECK(3), Agnes Kiesling CASALI(4) \& Marilene Henning VAINSTEIN(4)
}

\begin{abstract}
SUMMARY
The purpose of the present study was to compare the susceptibility to four antifungal agents of 69 Cryptococcus neoformans strains isolated from AIDS patients with that of 13 C. neoformans strains isolated from the environment. Based on the NCCLS M27A methodology the Minimal Inhibitory Concentrations (MICs) obtained for amphotericin B, itraconazole and ketoconazole were very similar for clinical and environmental isolates. Clinical isolates were less susceptible to fluconazole than environmental isolates. The significance of these findings and aspects concerning the importance, role and difficulties of $C$. neoformans susceptibility testing are also discussed.
\end{abstract}

KEYWORDS: Cryptococcus neoformans; Susceptibility; Antifungal agents

\section{INTRODUCTION}

Cryptococcus neoformans is an opportunistic yeast recognized as the etiological agent of human cryptococcosis. This widespread organism was noted to occur in immunosuppressed hosts especially those with AIDS, for whom disseminated disease is being increasingly reported ${ }^{25}$.

Cryptococcus neoformans is rarely isolated from healthy individuals and does not appear to be a common human commensal. The sporadic nature of human cryptococcosis, the extreme rarity of documented human-to-human transmission events ${ }^{3,12}$ and the high prevalence of $C$. neoformans in the environment indicate that human infection is acquired from environmental sources 5 . It was assumed that inhalation of infectious particles from avian excreta, the main natural source of environmental strains of the var. neoformans, is the major route for human infection ${ }^{5}$.

Based on the strong relationship between environmental and clinical C. neoformans strains ${ }^{5}$ and the few comparative studies carried out on antifungal susceptibilities ${ }^{9,10}$, the purpose of this study was to evaluate the susceptibility of 82 C. neoformans strains isolated in the state of Rio Grande do Sul, Brazil.

\section{MATERIAL AND METHODS}

Cryptococcus neoformans strains: a total of 82 strains were studied. Forty-eight isolates were obtained from cerebrospinal fluid (43), blood (3) and sputum (2) from 38 AIDS patients at the Hospital Universitário de Santa Maria, Santa Maria (RS, Brazil) from January 1996 through December 2000. Thirty-eight strains were obtained from patients during the initial diagnosis of cryptococcal infection and ten strains were obtained after the patients had been treated with amphotericin B or fluconazole. Other twenty-one clinical samples were kindly provided by Central Laboratory of Instituto de Pesquisas Biológicas da Secretaria da Saúde e Meio Ambiente in Rio Grande do Sul State - LACEN (fourteen) and by Hospital São Lucas (seven), from Porto Alegre. Environmental samples (thirteen) were from pigeon excreta originated from two different cities in the Rio Grande do Sul State, Porto Alegre and Santa Cruz do Sul, located in the South region of Brazil and separated apart by a distance of $150 \mathrm{~km}$. For C. neoformans isolation, $1.0 \mathrm{~g}$ of weathered pigeon excreta was added to $10 \mathrm{ml}$ sterilized saline solution with both chloramphenicol and ampicillin at $150 \mathrm{mg} \mathrm{ml}^{-1}$ each. After filtration through sterilized gauze, aliquots of $10^{-1}$ and $10^{-2}$ dilutions were inoculated onto birdseed agar plates and incubated at $37{ }^{\circ} \mathrm{C}$ up to 21 days. All strains were identified as $C$. neoformans by a positive Niger seed agar response, positive urease test, ability to grow at $37{ }^{\circ} \mathrm{C}$ and negative nitrogen test. The profiles of carbon compound assimilation were also determined ${ }^{5}$. Each isolate was identified as $C$. neoformans var neoformans by the canavanine-glycine-bromothymol-blue-agar method described by KWON-CHUNG et al. ${ }^{18}$.

Antifungal agents: the antifungal agents used were amphotericin B (Sigma), itraconazole and ketoconazole (Jansen Pharmaceutica), and fluconazole (Pfizer).

Susceptibility testing: we used the macrodilution technique ${ }^{19}$. RPMI 1640 medium (American Biorganics Inc.) containing L-glutamine was prepared according to manufacturer instructions. After reconstitution the medium was supplemented with glucose to obtain a final

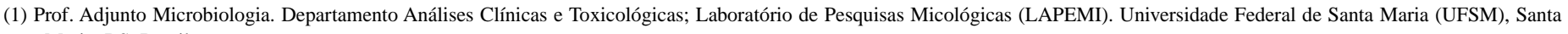
Maria, RS, Brasil.

(2) Hospital Universitário de Santa Maria, Santa Maria, RS, Brasil.

(3) Acadêmica do Curso de Veterinária, Bolsista do PBIC (CNPq), UFSM, Santa Maria, RS, Brasil.

(4) Programa de Pós-graduação em Biologia Celular e Molecular, Centro de Biotecnologia, Universidade Federal do Rio Grande do Sul (UFRGS), Porto Alegre, RS, Brasil.

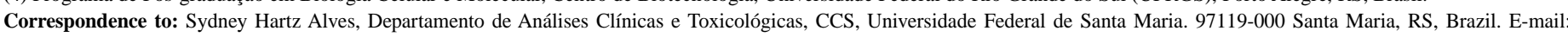
hartzsa@fatecnet.ufsm.br 


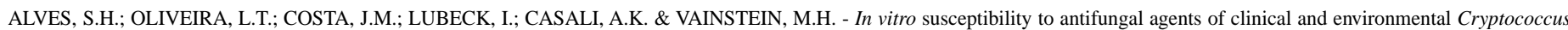
neoformans isolated in Southern of Brazil. Rev. Inst. Med. trop. S. Paulo, 43(5):267-270, 2001.

concentration of $2 \%$, and buffered to $\mathrm{pH} 7.0$ with 3-(Nmorpholino)propanesulfonic acid (MOPS; Sigma) to a final concentration of $165 \mathrm{mM}$. The procedures of inoculum preparation and incubation were those of the M27-A methodology ${ }^{19}$. The minimal inhibitory concentration (MIC) of amphotericin B was defined as the lowest concentration of drug which resulted in complete inhibition of visible growth. The MICs of azoles were defined as the lowest concentration of drug which resulted in an $80 \%$ reduction of fungal growth compared to control. The assays were read $48 \mathrm{~h}$ after inoculation. The data are reported as MIC ranges and MICs at which $50 \%$ and $90 \%$ of the isolates were inhibited. Candida parapsilosis ATCC 22019 and Candida krusei ATCC 6258 were used as quality control for the susceptibility tests.

\section{RESULTS}

Table 1 summarizes the in vitro susceptibilities of 69 clinical and 13 environmental isolates.

Table 1

In vitro susceptibility of $C$. neoformans strains to amphotericin B and azoles

\begin{tabular}{lccc}
\hline Antifungal agents and & \multicolumn{3}{c}{${\text { MIC }(\mu \mathrm{g} / \mathrm{ml})^{\mathrm{a}}}$} \\
\cline { 2 - 4 } strains group $^{\mathrm{b}}$ & Range & $50 \%$ & $90 \%$
\end{tabular}

Amphotericin B

Environmental

$0.0625-0.5$

0.125

0.25

Fluconazole

Clinical

Environmental

0.0625-0.5

0.25

0.5

0.125- 16

2.0

0.125- 16

0.5

8.0

4.0

\section{Itraconazole}

Clinical

Environmental

$$
\text { 0.031-0.25 }
$$

0.125

0.25

Ketoconazole

\begin{tabular}{llll} 
Clinical & $0.031-0.5$ & 0.125 & 0.125 \\
Environmental & $0.031-0.25$ & 0.0625 & 0.125 \\
\hline
\end{tabular}

a $50 \%$ and $90 \%$, MICs at which 50 and $90 \%$ of the strains, were inhibited, respectively; ${ }^{\mathrm{b}}$ Clinical isolates $(\mathrm{n}=69)$; environmental isolates $(\mathrm{n}=13)$.

Amphotericin B showed similar MIC ranges against the strains from both sources but MIC 50\% and MIC $90 \%$ were slightly more elevated for the environmental strains.

Fluconazole showed a broad MIC range, varying from 0.125 to $16 \mu \mathrm{g} / \mathrm{ml}$ for clinical and environmental isolates. The MICs $50 \%$ and $90 \%$ were more elevated for clinical than environmental isolates.

For itraconazole the MICs were within narrow ranges $(0.031$ $0.25 \mu \mathrm{g} / \mathrm{ml}$ ) for clinical and environmental isolates and the MIC 50\% was the same for all strains. The MIC $90 \%$ for clinical isolates was more elevated than environmental isolates. Ketoconazole showed narrow MIC ranges from $0.031 \mu \mathrm{g} / \mathrm{ml}$ to $0.5 \mu \mathrm{g} / \mathrm{ml}$. The MIC $50 \%$ for clinical isolates was more elevated than environmental isolates, but the MIC $90 \%$ was similar for clinical and environmental strains.

\section{DISCUSSION}

The concern about $C$. neoformans susceptibility is not recent ${ }^{4}$; however considering the newly standardized testing, the results currently obtained are becoming more appreciated because they allow interlaboratory comparisons. Our purpose was to compare clinical and environmental isolates because the emergence of resistance is an apparently rare phenomenon that encompasses development after long treatment with antifungals (secondary resistance) or primary resistance without former exposure to these agents ${ }^{8,23}$.

Our results are closely similar to those reported by other authors ${ }^{7,9,12,14,27}$ and seem to indicate susceptibility of $C$. neoformans strains to antifungal agents. However, some aspects about susceptibility tests deserve attention.

The narrow MIC ranges of amphotericin B have been pointed out to be a consequence of RPMI 1640 medium which may not be a good culture medium to warrant good $C$. neoformans growth and thus, could be hindering the detection of resistance $e^{8,11,23}$. Reports about amphotericin B-resistant $C$. neoformans are scarce $\mathrm{e}^{15,16,17,24}$ even during the AIDS era. Based on the M27-A methodology, our MIC ranges obtained for amphotericin B allow us to conclude that the clinical and environmental isolates studied are susceptible to the drug, as also reported by others ${ }^{7,9,14}$.

Fluconazole has been shown to be an effective alternative to amphotericin B in the treatment of cryptococcal meningitis and is the most commonly used antifungal agent in maintenance therapy for this disease $^{25}$. The majority of cases of meningitis due to $C$. neoformans resistant to fluconazole have been reported in AIDS patients after long treatments or prophylaxis with fluconazole ${ }^{1,2,21,22}$. Furthermore, a fluconazole resistant strain isolated from an immunocompetent patient without exposure to this triazole has been reported, which alerts that environmental strains can be primarily resistant to fluconazole ${ }^{20}$. So, cryptococcal susceptibility to fluconazole could be an important predictor of treatment success and MICs can be useful to monitor the possible development of resistance during therapy and to identify primary resistance $^{8,28}$. Our results based on MIC 50\% and MIC 90\% show that clinical isolates were less susceptible to fluconazole than environmental isolates even though MIC $\leq 16 \mu \mathrm{g} / \mathrm{ml}$ was observed in both groups of strains. However, the overall susceptibility of the southern Brazilian $C$. neoformans isolates to fluconazole was very similar to that reported for American isolates and in another Brazilian study ${ }^{9,27,28}$. FRANZOT \& HAMDAN $^{9}$ found that $100 \%$ of isolates from Minas Gerais (a central Brazilian state) were inhibited by $\leq 16 \mu \mathrm{g} / \mathrm{ml}$ of fluconazole, as also observed in the present investigation.

C. neoformans is extremely susceptible to itraconazole in vitro ${ }^{26}$; our data are similar to those reported by several other investigators who used the same methodology $y^{7,9}$. It seems clear that $C$. neoformans resistance to itraconazole is too rare and cross-resistance with fluconazole does not occur 1,6,21,22. However, IWATA et al. ${ }^{13}$ obtained an itraconazoleresistant $C$. neoformans strain after exposure to $\mathrm{N}$-nitro-nitrosoguanidine. The mechanism of action of itraconazole which blocks the lanosterol $14 \alpha$-demethylase and the NADPH-dependent-3-ketosteroid reductase in $C$. neoformans may have implications both for its potent antifungal activity and for its reduced development of cross-resistance compared to other azoles ${ }^{5}$. We did not observe differences in itraconazole MICs 


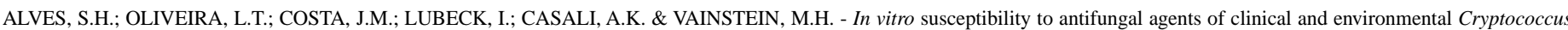
neoformans isolated in Southern of Brazil. Rev. Inst. Med. trop. S. Paulo, 43(5):267-270, 2001.

$50 \%$ between clinical and environmental isolates and our results are similar to those reported by others ${ }^{5,9}$.

Ketoconazole is not indicated for the treatment of cryptococcal meningoencephalitis but was included in the present study in order to evaluate a possible cross-resistance among azoles. The ketoconazole MICs observed were as low as that obtained for itraconazole and the interpretation is the same. The $3 C$. neoformans strains that showed fluconazole MICs $=16 \mu \mathrm{g} / \mathrm{ml}$ did not demonstrate elevated MICs for itraconazole and ketoconazole.

Finally, we found that clinical and environmental C. neoformans strains showed a similar pattern of susceptibility to amphotericin B, itraconazole and ketoconazole. The clinical isolates were less susceptible to fluconazole than the environmental isolates, possibly as a consequence of therapy with this agent. As postulated by others, during therapy of cryptococcosis the susceptibility tests of recurrent isolates may monitor the development of secundary resistance, because if susceptibility does not predict successful therapy, resistance should often predict therapeutic failure $1,2,6,8,15,16,19,21,22,23,24,28$.

\section{RESUMO}

\section{Suscetibilidade in vitro a antifúngicos, de amostras clínicas e ambientais de Cryptococcus neoformans isoladas no sul do Brasil}

Comparou-se a suscetibilidade de 69 amostras de C. neoformans isoladas de pacientes com SIDA com 13 amostras de $C$. neoformans isoladas do meio ambiente, frente a quatro agentes antifúngicos. Com base na metodologia preconizada pelo NCCLS (M27-A) as concentrações inibitórias mínimas (CIMs) obtidas para a anfotericina B, itraconazol e cetoconazol foram muito semelhantes nos dois grupos estudados. Todavia, frente ao fluconazol, os isolados clínicos evidenciaram menor sensibilidade do que os provenientes do meio ambiente. Alguns aspectos envolvendo a importância e dificuldades dos testes de suscetibilidade com Cryptococcus neoformans são também discutidos pelos autores.

\section{REREFENCES}

1. ARMENGOU, A.; POCAR, C.; MASCARÓ, J. \& GARCIA-BRAGADO, F. - Possible development of resistance to fluconazole during suppressive therapy for AIDSassociated cryptococcal meningitis. Clin. infect. Dis., 23: 1337-1338, 1996.

2. BERG, J.; CLANCY, C.J. \& NGUYEN, M.H. - The hidden danger of primary fluconazole prophylaxis for patients with AIDS. Clin. infect. Dis., 26: 186-187, 1998.

3. BEYT Jr., B.E. \& WALTMAN, S.R. - Cryptococcal endophthalmitis after corneal transplantation. New Engl. J. Med., 298: 825-826, 1978.

4. BODENHOFF, J. - Development of strains of Cryptococcus neoformans resistant to nystatin, amphotericin B, trichomycin and polymyxin B. Acta path. microbiol. scand., 73: 572-582, 1968.

5. CASADEVALL, A. \& PERFECT, J.R. - Cryptococcus neoformans. Washington, American Society of Microbiology, 1998.

6. COKER, R.J. \& HARRIS, J.R.W. - Failure of fluconazole treatment in cryptococcal meningitis despite adequate CSF levels. J. Infect., 23: 101-103, 1991.
7. DAVEY, K.G.; HOLMES, A.D.; JOHNSON, E.M.; SZEKELY, A. \& WARNOCK, D.W. - Comparative evaluation of Fungitest and broth microdilution methods for antifungal drug susceptibility testing of Candida species and Cryptococcus neoformans. J. clin. Microbiol., 36: 926-930, 1998.

8. ESPINEL-INGROFF, A. - Clinical relevance of antifungal resistance. Infect. Dis. Clin. N. Amer., 11: 929-944, 1997.

9. FRANZOT, S.P. \& HAMDAN, J.S. - In vitro susceptibilities of clinical and environmental isolates of Cryptococcus neoformans to five antifungal drugs. Antimicrob. Agents Chemother., 40: 822-824, 1996.

10. FROMTLING, R.A.; ABRUZZO, G.K. \& RUIZ, A. - Virulence and antifungal susceptibility of environmental and clinical isolates of Cryptococcus neoformans from Puerto Rico. Mycopathologia (Den Haag), 106: 163-166, 1989.

11. GHANNOUM, M.A.; IBRAHIM, A.S.; FU, Y.; SCHAFIQ, M. et al. - Susceptibility testing of Cryptococcus neoformans: a microdilution technique. J. clin. Microbiol., 30: 2881-2886, 1992.

12. GLASER, J.B. \& GARDEN, A. - Inoculation of cryptococcosis without transmission of the acquired immunodeficiency syndrome. New Engl. J. Med., 313: 266, 1985.

13. IWATA, K.; YAMASHITA, T.; OHSUMI, M.; BABA, M. et al. - Comparative morphological and biological studies on the itraconazole- and ketoconazole-resistant mutants of Cryptococcus neoformans. J. med. vet. Mycol., 28: 77-90, 1990.

14. JESSUP, C.J.; PFALLER, M.A.; MESSER, S.A. et al. - Fluconazole susceptibility testing of Cryptococcus neoformans: comparison of two broth microdilution methods and clinical correlates among isolates from Ugandan AIDS patients. J. clin. Microbiol., 36: 2874-2876, 1998.

15. JOSEPH-HORNE, T.; HOLLOMON, D.; LOEFFLER, R.S.T. \& KELLY, S.L. - Crossresistance to polyene and azole drug in Cryptococcus neoformans. Antimicrob. Agents Chemother., 39: 1526-1529, 1995.

16. JOSEPH-HORNE, T.; LOEFFLER, R.S.T.; HOLLOMON, D.W. \& KELLY, S.L. Amphotericin B resistant isolates of Cryptococcus neoformans without alteration in sterol biosynthesis. J. med. vet. Mycol., 34: 223-225, 1996.

17. KELLY, S.L.; LAMB, D.C.; TAYLOR, M. et al. - Resistance to amphotericin B associated with defective sterol $\mathrm{D}^{8,7}$ isomerase in a Cryptococcus neoformans strain from AIDS patient. FEMS Microbiol. Lett., 122: 39-42, 1994.

18. KWON-CHUNG, K.J.; POLACHECK, I. \& BENNETT, J.E. - Improved medium for separation of Cryptococcus neoformans var. neoformans (serotypes A and D) and Cryptococcus neoformans var. gatti (serotypes B and C). J. clin. Microbiol., 15: 535-537, 1982.

19. NATIONAL COMMITTEE OF CLINICAL LABORATORY STANDARDS - Reference method for broth dilution antifungal susceptibility testing of yeasts: approved standard M27- ${ }^{a}$. Wayne, National Committee for Clinical Laboratory Standards, 1997.

20. ORNI-WASSERLAUF, R.; IZKHAKOV, E.; SIEGMAN-IGRA, Y. et al. - Fluconazoleresistant Cryptococcus neoformans isolated from an immunocompetent patient without prior exposure to fluconazole. Clin. infect. Dis., 29: 1592-1593, 1999.

21. PAUGAM, A.; DUPOY-CAMET, J.; BLANCHE, P. et al. - Increased fluconazole resistance of Cryptococcus neoformans isolated from a patient with AIDS and recurrent meningitis. Clin. infect. Dis., 19: 975-976, 1994.

22. PEETERMANS, W.; BOBBAERS, H.; VERHAEGEN, J. \& VANDEPITTE, J. Fluconazole-resistant Cryptococcus neoformans var. gatti in an AIDS patient. Acta clin. belg., 48: 405-409, 1993.

23. PFALLER, M.A.; REX, J.H. \& RINALDI, M.G. - Antifungal susceptibility testing: technical advances and potential clinical applications. Clin. infect. Dis., 24: 776784, 1997. 
ALVES, S.H.; OLIVEIRA, L.T.; COSTA, J.M.; LUBECK, I.; CASALI, A.K. \& VAINSTEIN, M.H. - In vitro susceptibility to antifungal agents of clinical and environmental Cryptococcus neoformans isolated in Southern of Brazil. Rev. Inst. Med. trop. S. Paulo, 43(5):267-270, 2001.

24. POWDERLY, W.G.; KEATH, E.A.; SOKOL-ANDERSON, M. et al. - Amphotericin Bresistant Cryptococcus neoformans in a patient with AIDS. Infect. Dis. clin. Pract., 1: $314-316,1990$

25. POWDERLY, W.G. - Cryptococcal meningitis in HIV-infected patients. Curr. infect. Dis. Rep., 2: 352-357, 2000

26. SAAG, M.S.; CLOU, G.A.; GRAYBILL, J.R. et al. - A comparison of itraconazole versus fluconazole as maintenance therapy for AIDS-associated cryptococcal meningitis. National Institute of Allergy and Infectious Diseases Mycoses Study Group. Clin. infect. Dis., 28: 291- 296, 1999.
27. SANATI, H.; MESSER, S.A.; PFALLER, M.A.; WITT, M. et al. - Multicenter evaluation of broth microdilution method for susceptibility testing of Cryptococcus neoformans against fluconazole. J. clin. Microbiol., 34: 1280-1282, 1996.

28. WITT, M.D.; LEWIS, R.J.; LARSEN, R.A.; MILEFCHIK, E.N. et al - Identification of patients with acute AIDS-associated cryptococcal meningitis who can be effectively treated with fluconazole: the role of antifungal susceptibility testing. Clin. infect. Dis., 22: 322-328, 1996.

Received: 15 February 2001

Accepted: 22 August 2001 